http://revistaurbanismo.uchile.cl

\title{
El arte del paisaje
}

Oscar Prager (1876-1960)

\section{Filiación}

Paisajista alemán, residente en California entre 1903-1914, en Alemania (1914-1925), en Argentina (cuatro años), y en Chile desde 1926 hasta 1960, año de su fallecimiento. Fue consultor, director y proyectista de los parques de la ciudad de Oakland en U.S.A., proyectista en Argentina, y en su larga residencia en Chile, proyectista de numerosos parques públicos y privados. Su obra ha sido referida en el libro "Oscar Prager. El arte del Paisaje", de M. Viveros, et als., Ed. ARQ, P.U.C., 1997.

\section{Resumen}

Refiere el autor, en 1954, cómo el Arte del Paisaje, sobre cualquier otro, está en contacto íntimo e intenso con la vida del hombre, incluyendo en sí todas sus relaciones con el mundo externo. Con él, el hombre puede, si quiere, crear el marco perfecto para la vida perfecta, misión suprema de la humanidad.

Palabras clave

Paisajismo, Oscar Prager.

\begin{abstract}
Oscar Prager, in 1954, describes how the art of landscaping more than any other, is in intense and intimate contact with the life of the human being, including within itself all of his or her relationships with the external world. With landscape art, human being can, if it be desired, create a perfect framework for a perfect life; the supreme mission of humanity.
\end{abstract}

\section{Key words}

Landscaping, Oscar Prager.

\section{Sumario}

[La esencia del arte del paisaje]

[Pintura paisajista]

[El cine, la pintura paisajista, y el arte del paisaje]

[El carácter de un paisaje]

Referencias 

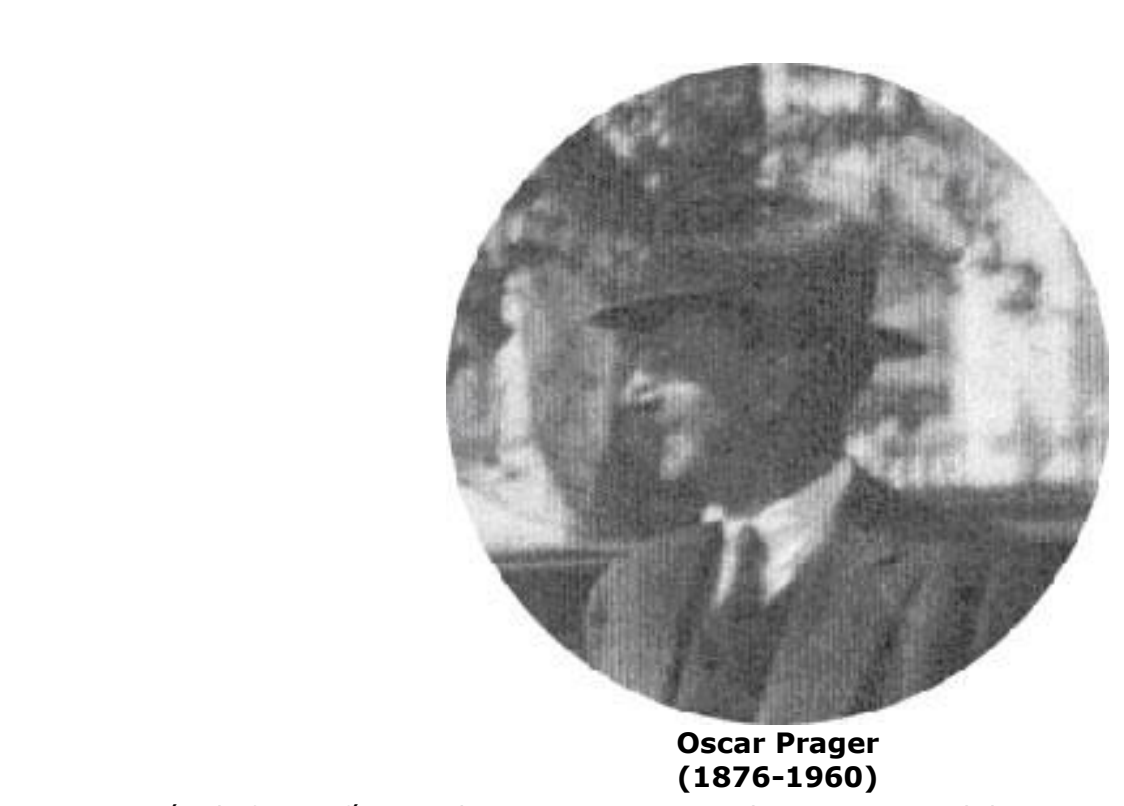

Fte.: Sección de fotografía tomada por K. Brunner en el Parque Forestal de Santiago en 1931. en Archivo K.B. en Viena. Gentileza de Magda Brunner de Hoyos y de Andreas Hofer, desde Viena, 1997.

\section{[La esencia del arte del paisaje]}

El arte del paisaje, con su sentido, leyes, limitaciones y relación con las demás artes ha sido el menos estudiado de todos. En escasas ocasiones se han ocupado de él filósofos y estetas, como Schopenhauer y Oscar Bie. Poco precisas son las afirmaciones del primero. Basta señalar su creación de un nuevo arte, "el arte del juego de aguas" (schöne Wasserleitungskunst), en realidad sólo un factor secundario en la arquitectura paisajista. Notable falta de claridad denota esta otra fórmula del mismo filósofo:

"Para apreciar las bellezas del mundo de las plantas no es menester que el arte venga a presentárnoslas, se ofrecen a nosotros por si mismas, pero considerado desde el punto de vista de la reproducción artística, el mundo vegetal entra en la esfera de la pintura del paisaje".

¿Acaso puede existir goce estético alguno sin la mediación del arte? Oscar Bie, por su parte, en su libro "Entre las Artes", confiere una segunda categoría al arte del paisaje, debido a que su materia estaría regida más bien por leyes naturales propias que por la voluntad del hombre. Este argumento surge, sin embargo, de la dificultad que hay para idear y realizar la obra perfecta en el arte del paisaje. Dominando, empero, esta materia, no hay razón que impida lograr en este arte soluciones que nada tengan que envidiar las más sublimes creaciones musicales.

Llamo este arte "Arte del Paisaje". Dos otras denominaciones "Landscape Architecture" y "Gartenkunst", o sea, "Arquitectura Paisajista" y "Arte de los Jardines", no consiguen señalar, sino de un modo limitado, su sentido y alcance. No sólo en los jardines y 
parques, sino en el Paisaje mismo, en su concepción más amplia, ha de manifestarse este arte. $\mathrm{Ni}$ es una arquitectura propiamente tal, aunque le interesan también las masas, las proporciones y las armonías. Dondequiera que el hombre se empeñe en modificar las formas de la naturaleza, se trata del arte del paisaje, ya que tal intervención debe ajustarse siempre a leyes estéticas a la vez que utilitarias. La solución perfecta debería identificarse con el cumplimiento común de ambos dictámenes. Empero, puede haber una transformación netamente estética de la naturaleza, exenta de todo motivo utilitario.

Tal vez llegue a comprenderse mejor la esencia del arte del paisaje, estudiando su correlación con otras artes. Empezaremos por compararle con un arte desligado de todo fin objetivo, la música. Lo mismo que el arte del paisaje, la música se vale de un objeto natural y de su función para componer una obra de arte enteramente libre de las manifestaciones de la naturaleza. El aire y sus ondas se someten, mediante los más diversos instrumentos y aun de la garganta del hombre, a ciertas reglas, que investigadas científicamente proporcionan resultados matemáticos curiosos. Tanto difieren los sonidos así formados de los ruidos que produce la naturaleza, que puede afirmarse que cuanto más se asemejan, menos arte habrá en los primeros. El arte así engendrado se distingue de las demás creaciones artísticas por su existencia fuera de toda dimensión, a no ser que se considere el tiempo como una cuarta dimensión. No obstante, precisamente este arte logra conmover lo más hondo de nuestro ser, traspasa las funciones puramente decorativas y parece ponernos en contacto con algo que, una vez más, nada tiene que ver con la naturaleza, sino más bien con algo más allá de lo natural, algo relacionado con las causas más profundas de nuestra existencia. Surgen así en la música, empleando las formas naturales más simples, obras de arte magníficas y trascendentales.

En la arquitectura lo primero es el fin. Han de crearse recintos para vivir y para trabajar, para la devoción y el recreo. El arte entra a actuar en tales creaciones sólo después de haberse resuelto el problema objetivo conforme a sus existencias. Arquitectura sin fin alguno es la escultura, cuyo sentido no consiste en imitar un objeto natural cualquiera, sino de conseguir una armonía de masas. Tiene la arquitectura, sin embargo, otra función: la creación de interiores, que si bien es cierto deben cumplir un fin determinado, pueden convertirse en obra de arte por la armonía de sus proporciones y colorido. Aquí se vislumbra un arte aún desconocido. Como complemento de la escultura, que se ocupa en cierto modo de la epidermis del espacio, podrían idearse interiores desligados de todo fin, el espacio interior, lográndose obras de arte puro, una especie de escultura negativa. Insinuaciones de ello ofrecen las catedrales góticas y sugestiones en este sentido la Gruta Azul, las cuevas de estalactitas y el interior de algunas conchas y flores.

Evidentemente, el arte del paisaje, en muchas de sus creaciones, tendrá que atenerse a un fin utilitario. Jardines, huertas, en general, todo parque o plantación, tienen tal finalidad. Pero, además, este arte puede también dedicarse a obras exentas de todo fin utilitario, puramente estéticas, un jardín o un parque destinado únicamente a ser contemplado, como una escultura o un cuadro. Los jardines japoneses, los 
receptáculos con paisajes en miniatura (Hako-Niwa, Bonseki), son muestras de un arte puro que se revela asimismo en el estilo japonés para arreglar flores.

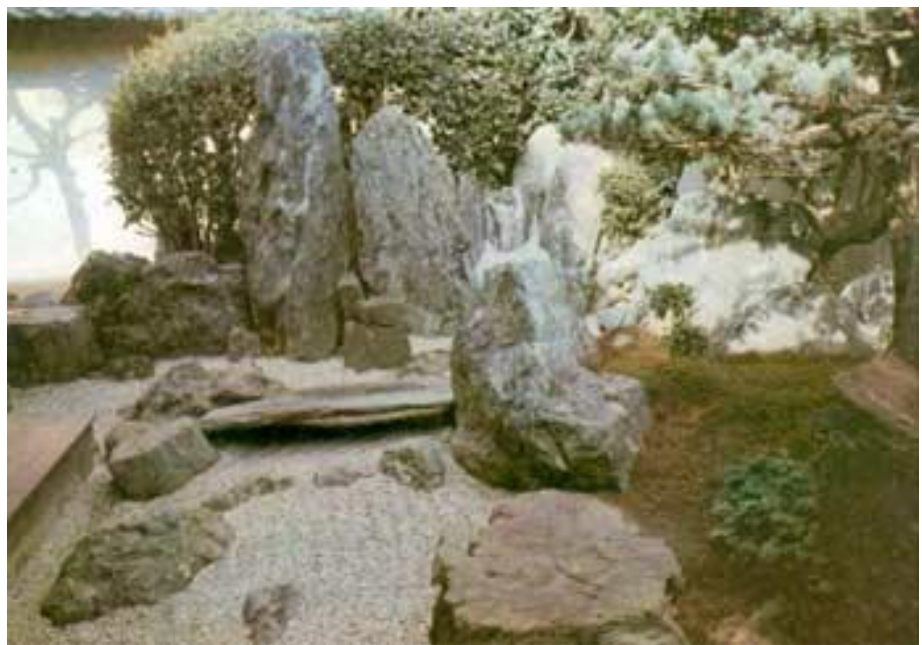

Arte japonés, período Muromachi, Jardín del Daisen-in, representando en miniatura, un vasto paisaje natural. Cada elemento del jardín tiene una función alusiva: los árboles y las rocas del fondo representan lejanas montañas entre las cuales corre un río (la grava) cruzado por un puente (la roca horizontal); sus elementos muestran un gran sentido de la perspectiva, Kioto.

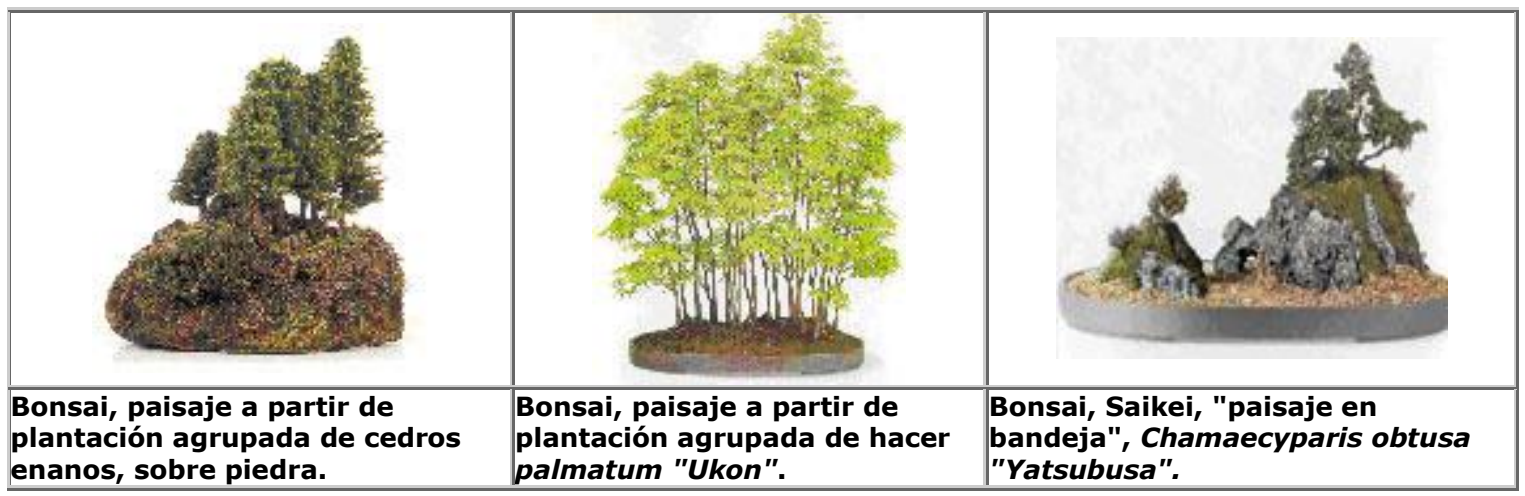

\section{[Pintura paisajista]}

Existe otro arte relacionable con el arte del paisaje, la pintura paisajista. Se presentan aquí paralelos interesantes entre dos artes que explican la relación que guardan entre sí el arte del paisaje y la pintura paisajista. Son éstos la danza y el cine. El movimiento como arte se muestra en forma primitiva en los juegos artificiales, ya más desarrollo en los juegos de agua (die schöne Wasserleitungskunst, de Schopenhauer) y de gran perfección en la danza. Contamos ahora con un invento que permite representar el movimiento. Algo enteramente nuevo y sin precedentes. Nos proporciona la posibilidad 
de un nuevo arte. La misión artística del cine es la representación del movimiento. Todo lo demás es superfluo. El elemento novelesco, lo mismo que en la pintura, es de segundo orden. Inmediatamente nos damos cuenta de que el film ofrece mayores posibilidades a la representación del movimiento que la danza. El artista domina mejor sus medios de expresión. No me refiero, se entiende, a la fotografía del movimiento en la naturaleza. Jamás eso sería arte, como tampoco puede considerarse arte la fotografía de un objeto natural cualquiera. Habría que añadirle muchos factores más. El fotógrafo, al suprimir todo lo superfluo, puede captar una línea o una impresión, pero jamás se igualará a la obra de arte que un artista crearía con el mismo motivo. La fotografía de una ola nunca llegará a ser la ola representada por Hokusai. Análogamente, el movimiento fotografiado de una ola no podrá ser la obra de arte creada por el artista que interpretaría el movimiento de la ola, así como Hokusai su forma. Únicamente el cine dibujado podría crear la obra de arte relativo al movimiento. Esto se ha ensayado, pero desgraciadamente no por artistas.

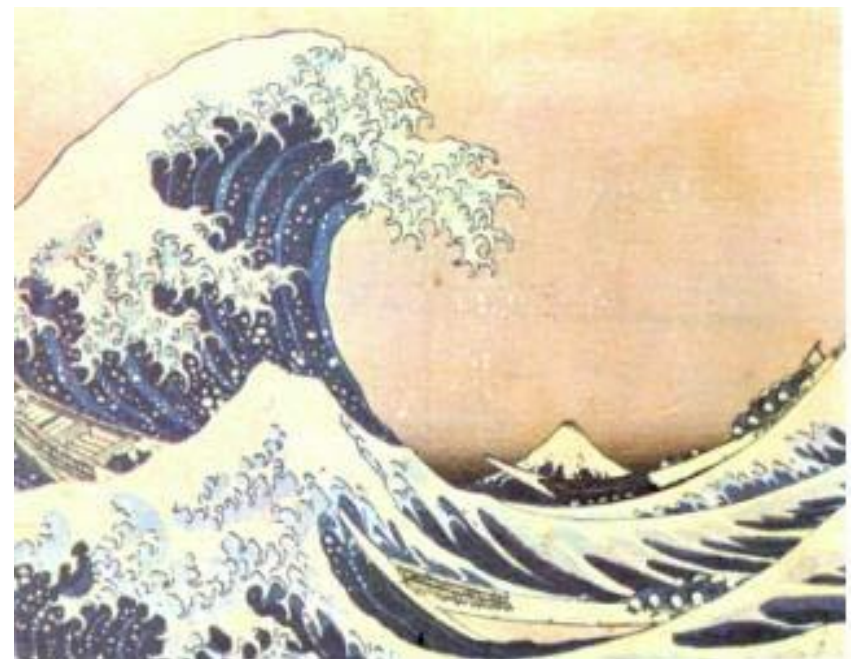

Arte Japonés, período Edo, "El monte Fuji visto entre las olas", estampa de Katsushika Hokusai (1829-1831). Museo Nacional de Tokio.

\section{[EI cine, la pintura paisajista, y el arte del paisaje]}

El adelanto técnico del cine conduce a creaciones como "Fantasía". Pero Walt Disney no es artista, sino dibujante, y "Fantasía" es una profanación. La trama es, como en todas sus demás películas, de mal gusto. Muestra, eso sí, las posibilidades técnicas que se ofrecen al artista. La obra de arte relativa a la estilización del movimiento es todavía cosa del futuro. Si comparamos ésta con la danza, notamos que le falta ante todo cuerpo. Por vastas que sean las posibilidades del cine dibujado para neutralizar las restricciones que el cuerpo impone en la danza del artista, se presenta, en cambio, la limitación de tener sólo dos dimensiones. Es la misma relación que hay entre la pintura paisajista y el arte del paisaje. Podría decirse que este es a la pintura paisajista 


\section{REVITAOES

como la danza al cine. A pesar de esto, su parentesco es estrecho, su fructificación recíproca considerable, pues ambas están regidas por las mismas leyes estéticas. Si el artista estiliza un movimiento en el film, se atiene a las mismas reglas que valen para crear el movimiento en la danza. El arquitecto paisajista observa las mismas normas que dominan las obras del pintor paisajista.

Resulta, pues, interesante comparar el desarrollo y las leyes de la pintura paisajista con las del arte del paisaje. De ambos la pintura paisajista es la que nace primera, a lo que parece oponerse la historia del arte del paisaje. Esta empieza, por lo general, con el jardín del Edén, conduce a través de los jardines colgantes de Seminarís y el túsculo de Plinio, hasta los jardines conventuales de la Edad Media; desde los jardines del Renacimiento y del Barroco hasta los parterres franceses. Luego, en tiempos de Chambers y Repton, cuando en Europa se empezaba a conocer el arte chino y japonés, se transforma el "estilo arquitectónico" en un "estilo natural" o "inglés" y termina, a través de Pueckler y Lenné, en el estilo de nuestros tiempos.

La pintura paisajista más antigua y perfecta existió en la China y el Japón y fue en estos países donde se crearon las primeras obras de arte del paisaje vivo.

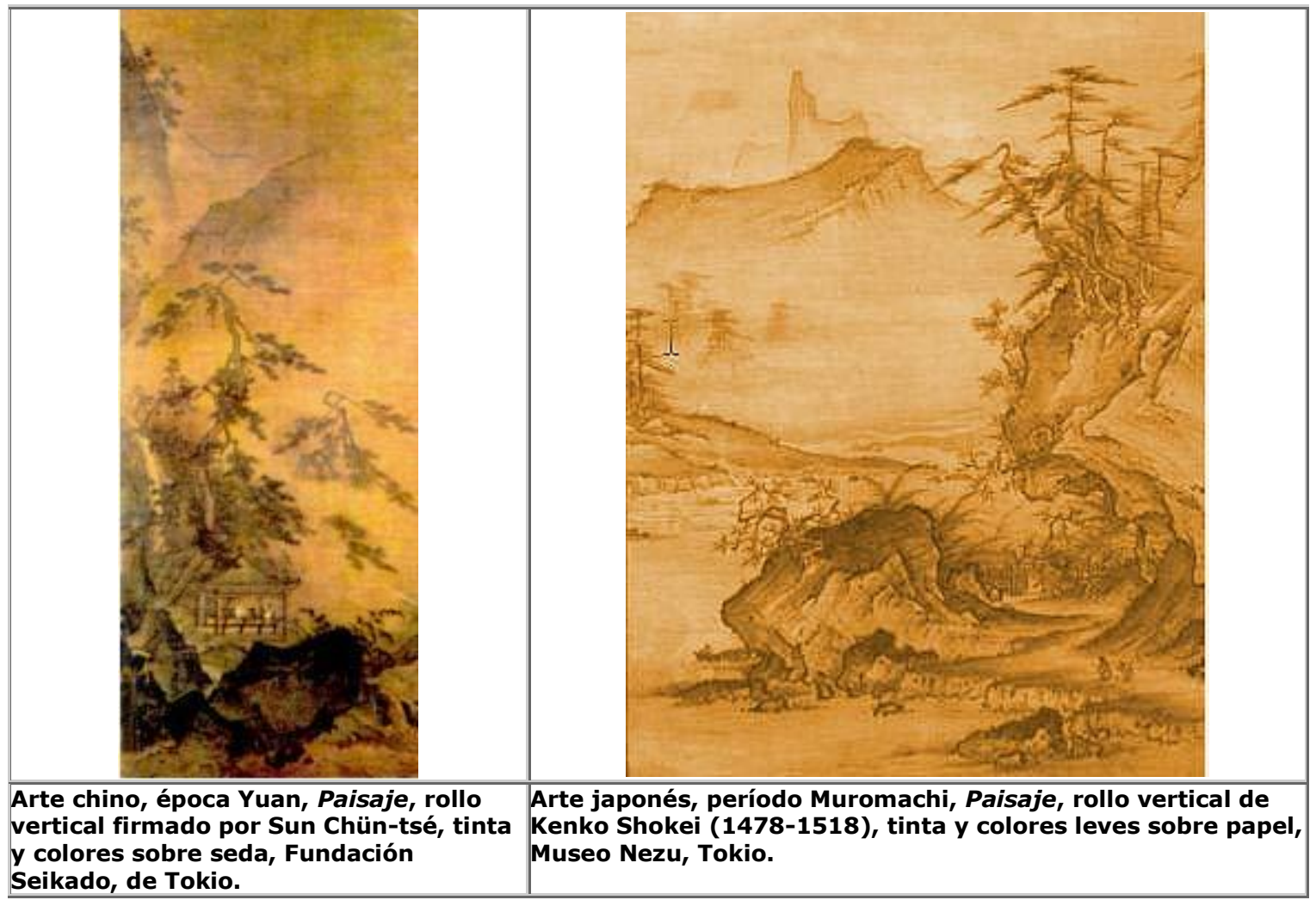




\section{REVISTA DE

http://revistaurbanismo.uchile.cl

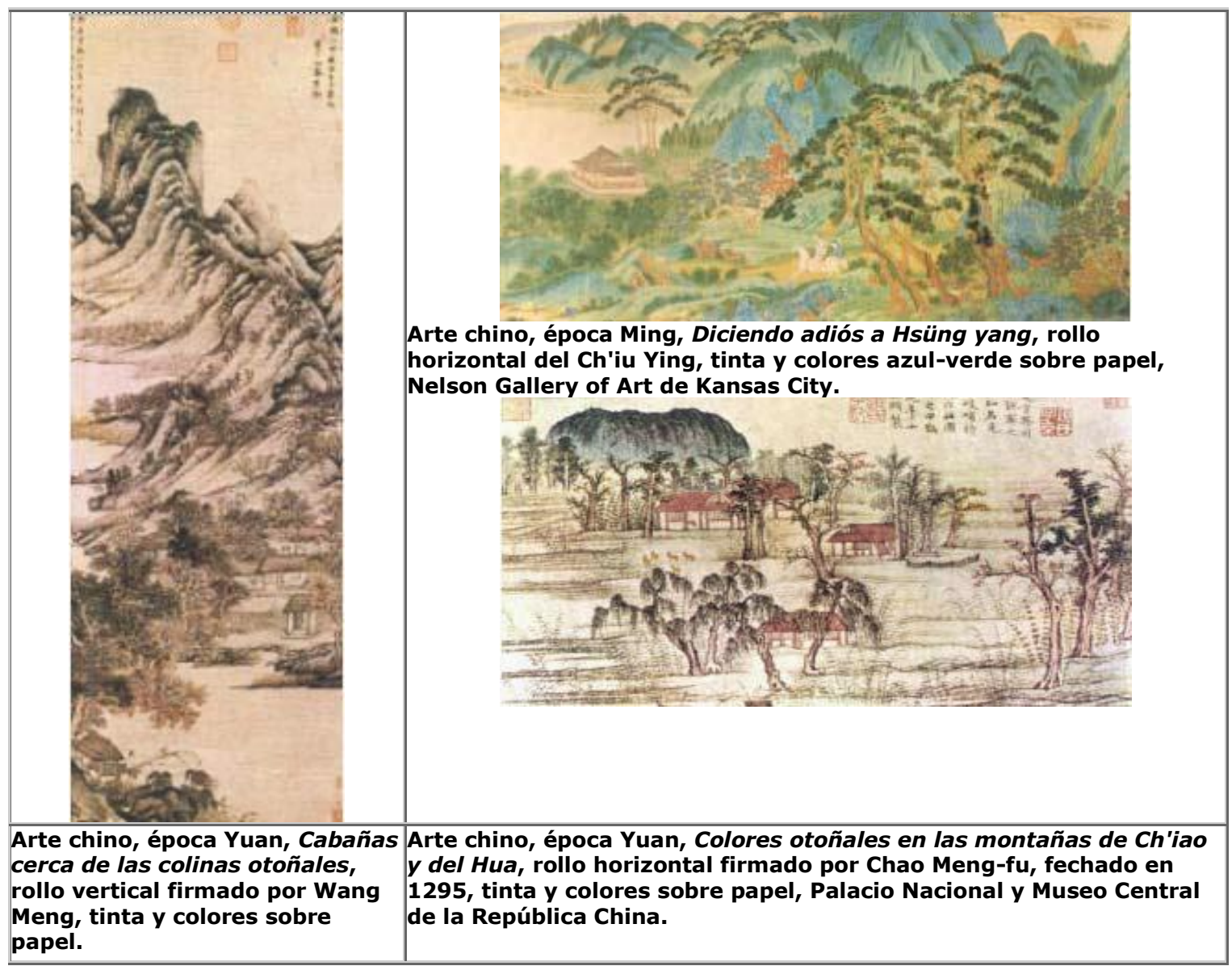

Para el mundo occidental la pintura paisajista es un arte relativamente nuevo. En sus comienzos es mero fondo de cuadros sagrados; paulatinamente van disminuyendo las representaciones religiosas y el paisaje logra dominar más y más el cuadro hasta que por último se producen los grandes paisajes con figuras de tamaño reducido: "María en la huida a Egipto", "El buen samaritano" o bien, posteriormente, un templo, una ruina, un molino, como complemento del paisaje. El concepto de "statage" se mantiene hasta nuestros días y sólo en el siglo diecinueve tenemos paisaje propiamente dicho.

El error se debe aquí a la interpretación del concepto "jardín". Se trata de la historia del jardín o del paisaje como obra del arte. Sombra, frutos, flores, todo eso ya se apreciaba sin duda en el Edén, pero no podemos llamarlo arte. El goce que nos proporciona la naturaleza no es el mismo que aquel que sentimos ante una obra de arte. En otras palabras, todo lo que comprendemos bajo el concepto "goce de la naturaleza", sea en un jardín o un parque, no es creación del artista del paisaje. Existe, es cierto, una contemplación de la naturaleza. Todo individuo educado en el estudio de obras de arte, al contemplar un paisaje busca en él formas, líneas y colores 
armoniosos, sacados de las confusas impresiones de la naturaleza. Tales visiones no son, sin embargo, un goce natural, sino una actividad del espíritu, la que tratándose de tipos creadores se cristalizan en una manifestación de arte. Idéntica labor corresponde tanto al pintor paisajista como al artista del paisaje, no una mera reproducción de la naturaleza, ni su mejoramiento, ni su hermoseamiento, sino la creación de una obra de arte que yace en la naturaleza como la estatua en la piedra.

Si comparamos la estatua que se alza de la piedra, como una obra del arte del paisaje, notaremos de inmediato la curiosa relación que la última guarda con su materia más importante. La planta vive, crece y cambia con las estaciones del año. Por lo común no hay relación entre la substancia y la obra de arte hecha con ella. Se comprende que cada materia reclama su técnica propia. Pero ni el lienzo ni la pintura al óleo, ni la seda ni la tinta china, ni el papel ni el lápiz influyen en el valor artístico del cuadro, como tampoco las hebras de lana determinan la calidad artística de la alfombra o del tapiz. No se aprecia el mérito artístico de una estatua considerando si es oro o bronce su materia. Si un escultor deseara atenerse a la misma dependencia que hay en el arte del paisaje entre la planta y la obra, debería esculpir en el bloque de mármol un peñasco, en otras palabras, estilizar la materia misma y no imponerle una forma ajena a su condición natural. Algo análogo ocurre en la orfebrería. Las piedras preciosas se trabajan y combinan según sus propios valores estéticos. Esto es lo que se ha de procurar en el arte del paisaje. Tener siempre presente que el material puede moldearse, intensificarse, combinarse estéticamente, pero que nunca le deberá falsear su estructura propia, forzándolo para que se adapte a una interpretación ajena a su ser. Este conocimiento puede solamente conseguirlo una educación visual de muchos siglos, ayudada por la pintura paisajista.

En tiempos en que aun no se conocía la pintura paisajista y faltaba la comprensión de la posibilidad de transformar un paisaje en una obra de arte, los arquitectos forzaban las plantas en los moldes propios de su arte. Árboles y arbustos ofrecían formas rígidas, contrarias a su carácter, tales como figuras de personas y animales, o bien asientos, arcos, pirámides, espirales o abstracciones matemáticas de su crecimiento natural, como cubos, bolas y setos vivos. La misma incomprensión frente a las posibilidades inherentes de la materia se manifiesta en los llamados parterres y arriates con dibujos de ornamentos, donde se empleaba la planta en la calidad de tierra colorante o piedrecilla multicolor. Respecto al enlace del edificio con sus inmediaciones, algo de suma importancia, el único medio conocido eran terrazas, escalinatas, pilas, pérgolas y avenidas, que cumplían esta función de manera incompleta y a su vez reclamaban una unión con el paisaje.

El actual aspecto pictórico de los jardines del Renacimiento se debe a su abandono a través de los siglos y no concuerda con las atenciones de sus creadores. La hermosa vista, con los empinados cipreses, que se ofrece desde abajo sobre la Villa D'Este no se contempla en los planos originales. Estos cipreses son los supervivientes de todo un seto de estos árboles, que tapaba por completo el círculo y su fuente, asimismo el camino central y así eliminaba aquella vista. El camino sombreado es uno de los ejes laterales, con ese muro cubierto de musgo y con la fuente en la cual va cayendo de 


\section{REVISTA DE URBANISMO}

http://revistaurbanismo.uchile.cl

cuando en cuando un chorro de agua, en el plano primitivo se reduce a una pila alargada surtida por cien águilas bicéfalas del escudo austríaco, que vierten el agua por sus doscientos picos.

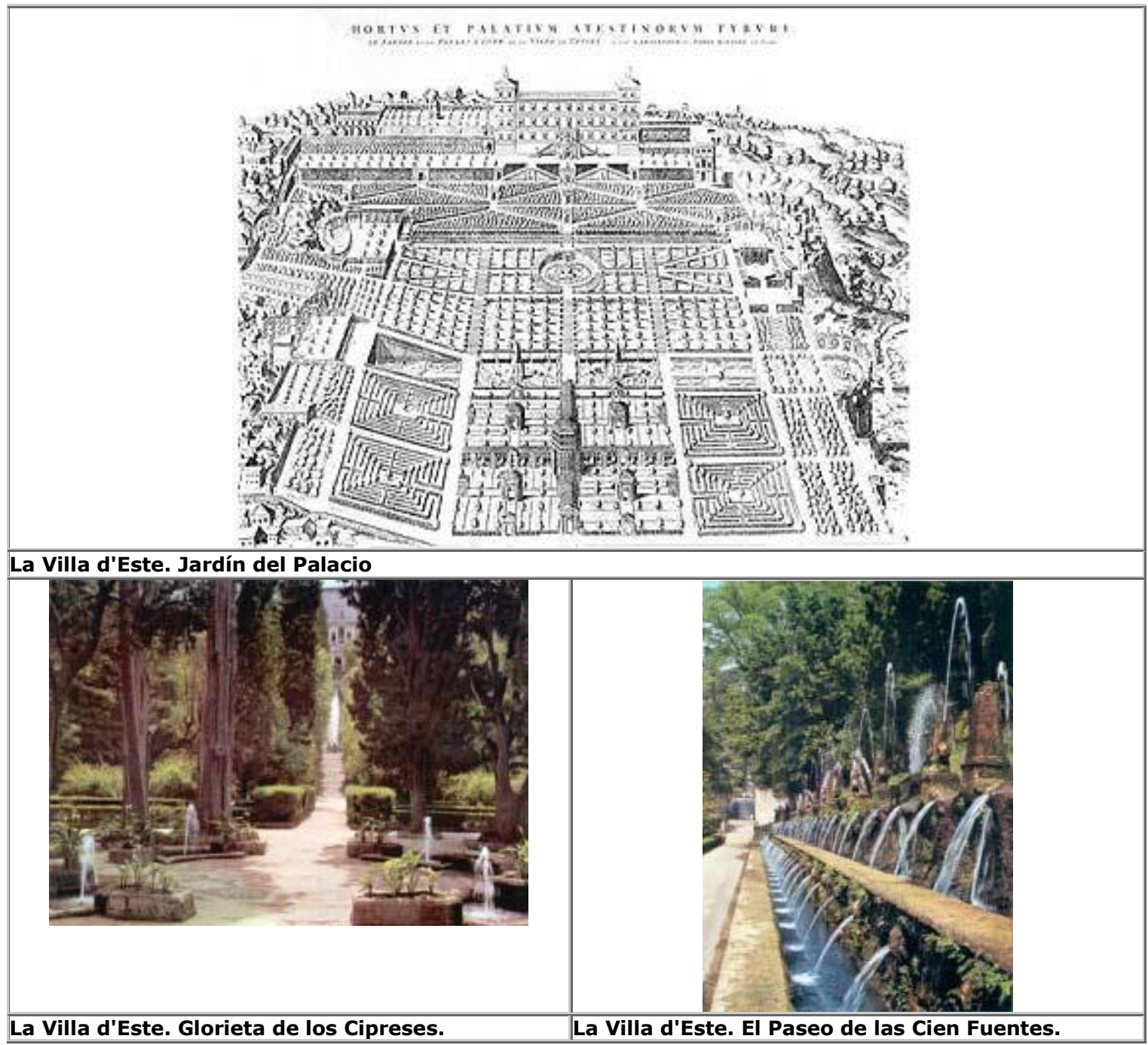

El misterioso monte de olivos en la Villa Medici, con sus escalinatas, hermas y con su olivar, en el proyecto es un cono artificial, a cuya cumbre conduce un camino en espiral, orillado por hileras de olivos. Las pilas y grutas contaban con sutilezas absurdas, como chorros de agua que inesperadamente mojaban al paseante, u otras fantasías de mal gusto. Son muchos los ejemplos que podrían citarse. Nunca se logró dar enlace con el paisaje circundante y nadie pensó en la composición artística de éste. 
Sólo doscientos años más tarde, a principios y mediados del siglo diecinueve, se comienzan a planear, en Inglaterra y Francia, los primeros jardines y parques de concepción paisajista. Las inspiraciones nacen al primer contacto con el arte chino y los pintores europeos de la época: Salvador Rosa, Nicolás Poussin, Claude Lorrain, entre otros: La dependencia espiritual que el arte del paisaje tiene de estos maestros, evidencia la frase de Samuel Ward ("Essay on the different situations of gardens"): "Perhaps the landscapes of Poussin are the best instructor which a gardener of genius and taste can follow", como asimismo lo expresado por Shenstone, el más eminente arquitecto paisajista de su tiempo: "I think the landscape painter is the gardener's best designer". Desgraciadamente, esta influencia indujo a los arquitectos paisajistas a recargar sus proyectos con motivos románticos y sentimentales. Aun a comienzos del siglo diecinueve, las obras de los grandes creadores de jardines, como Lenné, Pueckler y Sckell, demuestran estos defectos.

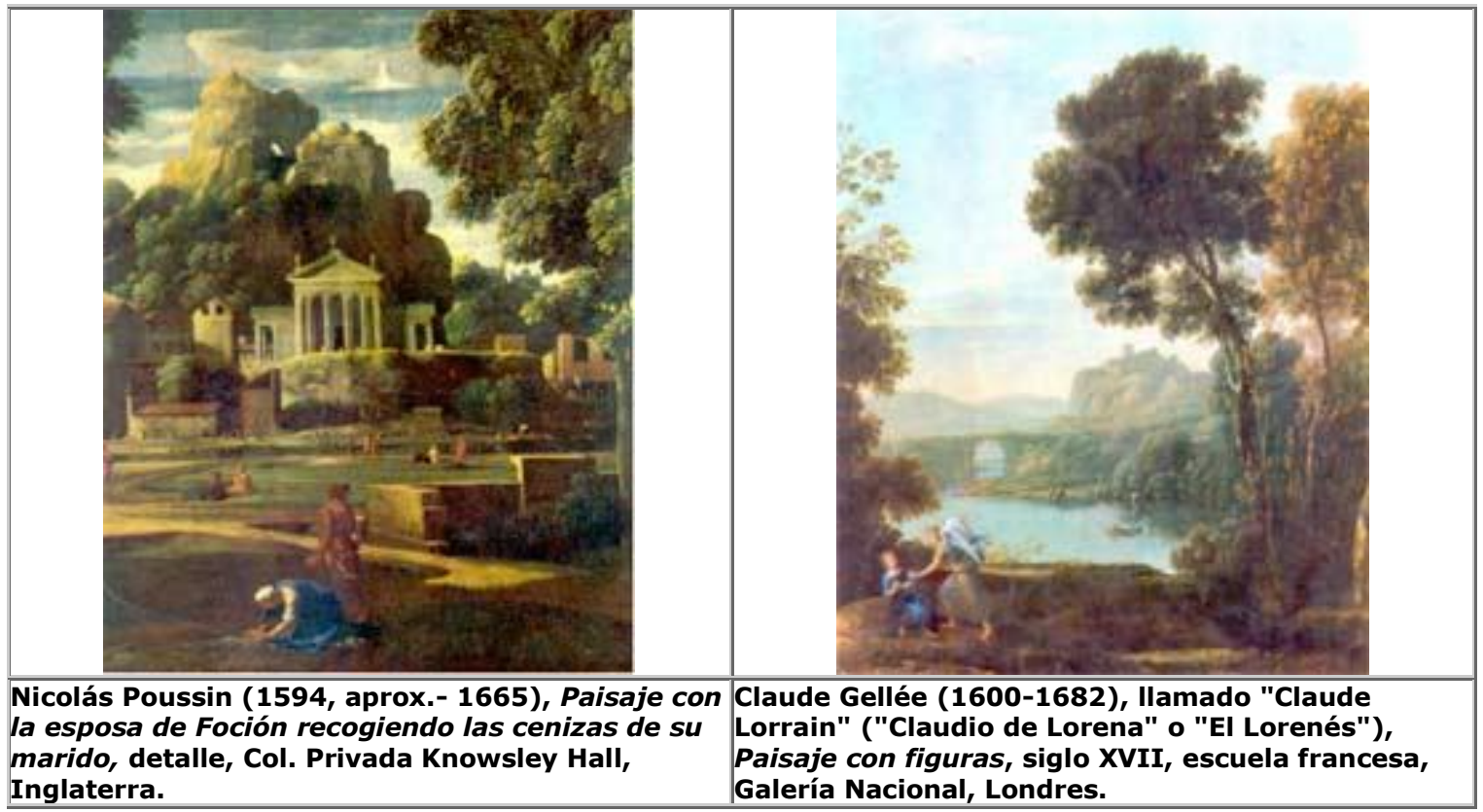

De por sí un paisaje no es ni bello ni feo. Estos son conceptos humanos y es el individuo de constitución artística quien siente las formas, líneas y colores de un paisaje como leyes estéticas latentes en éste. Idéntica sensación experimenta el pintor y en sus cuadros acentúa, simplifica o intensifica estos sentimientos y dictámenes. Misión del arquitecto paisajista es ahora manifestar estas formas, líneas y colores en el paisaje mismo, reforzando algunos, subrayándolos y eliminando a su vez las influencias perturbadoras para que así se exteriorice claramente el ritmo neto del paisaje. No existe paisaje en la naturaleza que con tal tratamiento no se pueda transformar en un valor estético superior. Ilustración interesante e instructiva sobre 
este proceso sería una colección de reproducciones de obras de pintura paisajista y de fotografías de los motivos que en la naturaleza les han servido de base.

Esta planificación del paisaje comienza por adaptar toda obra humana a las condiciones peculiares del paisaje. Cada una de estas empresas obedece primeramente a razones prácticas. Pero "hermoso" y "práctico" no necesitan ser antagónicos. Paisajes, resultados de una agricultura floreciente, pueden causar un placer estético mayor al que produce un trozo de naturaleza, puesto que este placer no depende del objeto mismo sino de las leyes estéticas y su aplicación. La estructura de una ciudad, de una aldea, de una casa de campo, de una finca, de una fábrica, de un dique, de un ferrocarril, de un puente, puede satisfacer simultáneamente lo necesario y lo estético y debe unirse y vibrar con el ritmo del paisaje.

Ahora estamos rodeados de paisajes destruidos, de ciudades maltrechas, de obras de construcción crudas, de feísimas líneas de ferrocarril, de tediosas autopistas, acompañadas a menudo de estúpidas hileras de árboles y avisos absurdos. Todos estos fenómenos no son indispensables, sino únicamente una confirmación de nuestros atrofiados instintos estéticos. Pueden estos problemas también resolverse en forma perfecta. Por su magnitud, su solución corresponde a la nación entera.

Los edificios que vayan colocándose en un paisaje deben tomar el ritmo de éste y aunarse con él. Tratándose de construcciones monumentales, la influencia formal suele abarcar grandes extensiones del paisaje. Se enlazan mediante redes axilares de caminos, arcadas, pérgolas, terrazas, escalinatas y pilas de agua. Sin embargo, estos predominios llegan a un punto en el que ha de hallarse la transición entre ellos y el paisaje mismo. La arquitectura es absorbida por el parque. En construcciones más pequeñas, el jardín basta para rematar el motivo de la caso en el paisaje. De todos modos es imprescindible la conexión. Ni aun la casa más pequeña puede colocarse sin algún enlace con el paisaje. Ni en el parque, ni en el jardín son imprescindibles los caminos en curvas y de bordes paralelos. Más interesantes y más de acuerdo con su carácter de senderos son aquellos de orillas irregulares que permiten al césped y a las flores menudas entrar en ellos. Sólo el trazado de caminos en combinación con la arquitectura debe ser de líneas rectas, formas rectangulares que muestren el efecto de una rigidez lógica.

La planta es el material más importante para lograr la conexión entre edificio y paisaje y el empleo de ella no está regido por la arquitectura, sino por las leyes estéticas del arte del paisaje. Estas leyes son dirigidas por las posibilidades de la transformación del paisaje, por el material disponible y por el artista. En China y Japón se han basado estas leyes estéticas en ideologías religiosas y filosóficas. Así en la selección de un sitio para una casa, en la combinación de diferentes variedades de plantas, en el mismo arreglo de flores. Pero todas estas fórmulas son nada más que un disfraz para leyes estéticas. 


\section{[El carácter de un paisaje]}

La planificación de la plantación en el paisaje debe acentuar y estilizar el ritmo de éste. No debe tener el carácter de un concepto arquitectónico. La alameda es una forma arquitectónica. Debe ser rectilineal, tener un comienzo, la entrada, y un fin, un monumento o un edifico. Caminos sin estos requisitos arquitectónicos no son alamedas o avenidas y nunca deben ser orilladas con líneas de árboles en distancias uniformes. Esto destruye por completo el ritmo del paisaje. Un bosque o cualquier grupo de árboles nunca deben ser plantados en líneas rectas y los árboles a igual distancia, ni las curvas de un río o de un lago orilladas en esta forma. Tampoco se deben usar flores con este fin.

El carácter de un paisaje sólo logra expresarse mediante su vegetación propia u otra afín, que se ha formado en el mismo clima y una constitución similar de tierra. Aun si contáramos con palmas adaptables a temperaturas bajas, no deberíamos plantar palmares en las mesetas de Escocia. No obstante, puede ampliarse la vegetación nacional con la similar de otro país. Así las encinas europeas con las de Nueva Inglaterra con su follaje otoñal multicolor, los arrayanes de Chile con los myrtus de Europa, el oleander de Italia con la carpintería de California. Así pertenece ya al paisaje de Italia el áloe, que llegó de México.

La planta, como ser vivo ofrece al hombre una oportunidad excepcional para ordenarla en todas sus manifestaciones e indicar así el destino histórico de la humanidad, el dominio creciente de su intelecto sobre la naturaleza que encuentra. Hay dos caminos para esto, la crianza y la poda. Este dominio se ha manifestado hasta ahora solamente en una forma poco satisfactoria. La dificultad es establecer definitivos valores estéticos, que han producido frecuentemente resultados imperfectos, como en los ensayos de crear nuevas variedades de la raza canina. En las plantas estamos comenzando a avanzar en dirección de una mejora estética de la materia prima, pero las posibilidades son ilimitadas y fantásticas. Los errores de los criaderos fueron nada más que deficientes ideales estéticos, como el tamaño exagerado de la flor misma sin tomar en consideración las proporciones de la planta, como si la Venus de Milo fuera más perfecta con una cabeza de doble tamaño, y la preferencia de la flor excesivamente doble. Pero esto ya pertenece al pasado, el futuro va a ver una evolución sorprendente. Esta mejora del material por cultivo se extiende hasta los animales, como lo muestran los ciervos enanos en los parques de Japón, los peces colorados con colas de abanico en las lagunitas de China y los ensayos hechos por el Rey Fernando de Bulgaria de cruzar mariposas tropicales con las de su país.

Otra manera de influir en la planta es la poda. Tratándose de árboles frutales, ella persigue un fin práctico, aumentar la producción frutal y mantener las ramas a una altura conveniente para la recolección de la fruta. También necesitan poda los árboles y arbustos en los jardines y parques. Pero según otros sistemas y por otras razones. Es un gran arte, que requiere mucha compenetración de la estructura de la planta, su 
moderación lógica y el desarrollo artístico de su crecimiento. Un arte desconocido practicado generalmente por gente incompetente. Parece curioso que haya una sola raza, cuyos elementos, por modestos que sean, poseen una sensibilidad tal para la forma estilizada (artísticamente concebida) de la planta que ha llegado a convertirse casi en instinto; son los chinos y los japoneses. Poseen una manera sobresaliente de tratar a los árboles, arbustos y flores en sus jardines y parques; igualmente las especies enanas y los arreglos de flores en sus platos y jarrones. Para estos últimos las hojas, flores y botones están sometidas a una técnica muy complicada relativa al masaje y modo de encorvar los tallos, la eliminación de partes superfluas para conseguir así un determinado ritmo en el movimiento del conjunto. Los árboles enanos muestran hasta qué grado es posible influenciar el carácter de una planta.

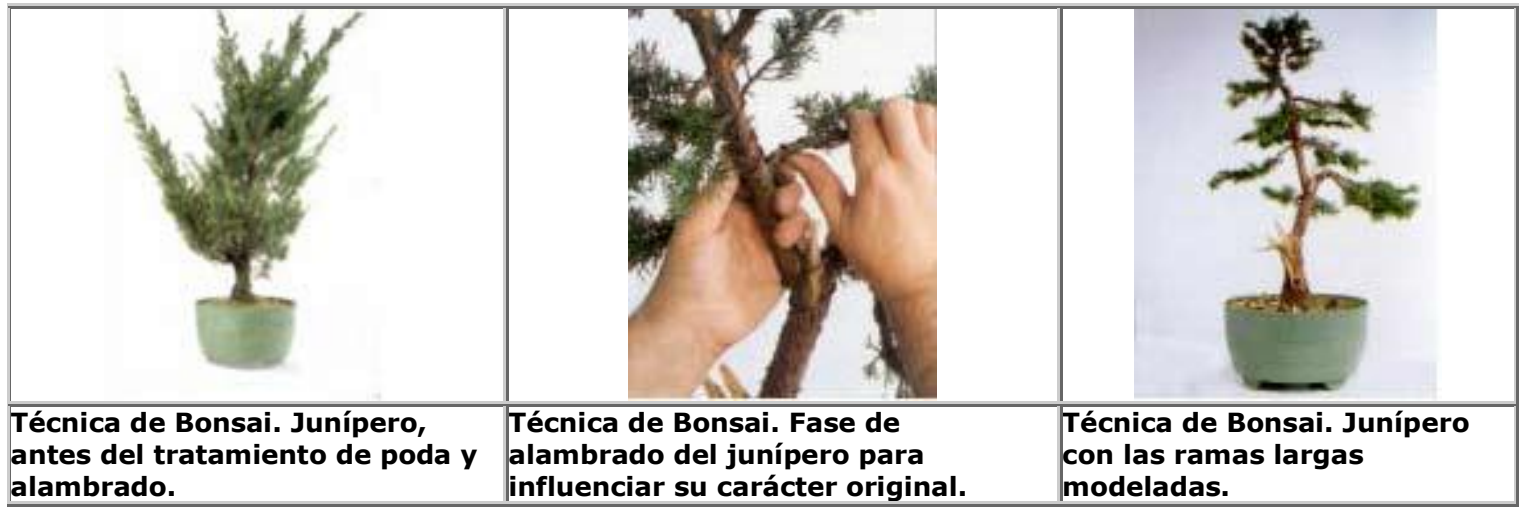

Un parque o un jardín no estará jamás terminado en el sentido en que lo está una estatua, una casa, un cuadro: como una obra de arte. La planta vive y crece y reclama constantemente la mano del artista. Una ocupación que debería corresponder a su dueño, al aficionado, un juego de gran interés, muy exigente en cuanto a su sensibilidad artística. Es una oportunidad para cooperar en la creación de una obra de arte, no adquirirla simplemente, aconsejado por un perito, para colgarla luego en la pared o bien arrinconarla. En los árboles debe evitarse ante todo un paralelismo excesivo de las ramas y una aglomeración de ellas en el interior de la copa, debido a las ramificaciones verticales. No es la poda exterior sino la intervención en el desarrollo des u estructura general, de manera que el árbol vaya adquiriendo con el correr de los años la configuración artística que le sea particular. Algunos de los árboles enanos de Japón tienen una edad de quinientos años y fueron podados año por año según las mismas leyes estéticas.

Son los grandes pintores paisajistas, Poussin, Claude Lorrain, Calame, Corot, Friedrich, Thoma y Boecklin quienes pueden servirnos de guía. Basta observar uno de los árboles que en el invierno pierden su follaje. El individuo educado en la contemplación de cuadros no tardará en entrever en la mezcla de sus ramas y ramillas negruzcas un delineamiento parecido a un aguafuerte que él puede sacar de esta confusión y establecer por la poda una armonía clara de las líneas. Lo mismo vale para el 
tratamiento de los arbustos. También aquí hay que intervenir en el núcleo de su desarrollo, no sólo para rejuvenecer el arbusto sino para lograr la expresión de sus rasgos pictóricos.
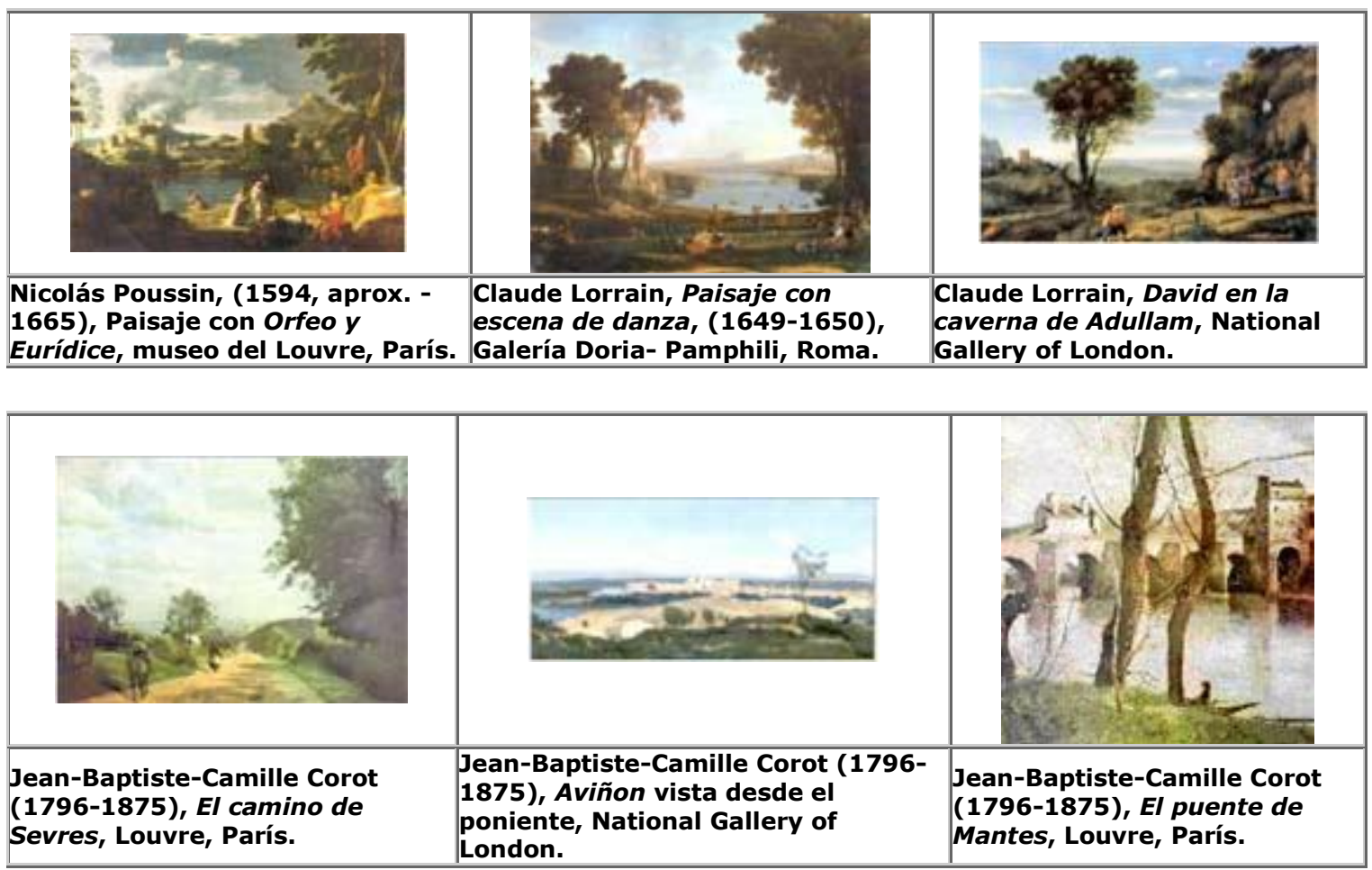

Todo esto es válido también para las flores. Cada planta puede transformarse en la obra de arte que el japonés coloca en un vaso, mientras que nosotros la dejamos en el jardín, porque es en el empleo de esta materia cromática donde aventajamos a los japoneses.

Son estas las labores que consiguen hacer comprender las bellezas del jardín. Por pequeño que sea, un jardín puede transformarse en una obra maestra, realizar un motivo, una idea de acuerdo con el tamaño del jardín y sus posibilidades. Un árbol en flor con una fuente mural. Un asiento, una estatua con un fondo de arbusto, unas pocas piedras con flores o áloes y ágaves. La manifestación más íntima del arte japonés, un jardincito para tomar té, puede tener como motivo: "Avena de las dunas en el viento".

Hay muchas cosas más que pueden contribuir a la belleza de los parques y jardines. Así, la iluminación, con sus grandes posibilidades. Los japoneses la han solucionado a su manera, con el farol de piedra. A nosotros nos tocará ligar el alumbrado con la 
arquitectura, con las terrazas, escalinatas, asientos o bien colgar en árboles vetustos grandes lunas que brillen a través de los follajes.

Integran el jardín aun los animales, el venado, los pájaros, peces, tortugas, mariposas y la luna, el sol y todas las estrellas. Los japoneses colocan una piedra especial que sirve de asiento allí donde a cierta hora se divisa la luna llena por entre el ramaje de un viejo pino. La llaman: "Piedra de la sombra de la luna".

Estas observaciones indican que el arte del paisaje, sobre cualquier otro, está en contacto más íntimo y más intenso con la vida del hombre, incluye en sí todas sus relaciones con el mundo externo y con él el hombre puede, si quiere, crear el marco perfecto para la vida perfecta, misión suprema de la humanidad.

\section{Referencias}

Fuente de este escrito: Anales de la Universidad de Chile, Memorias Científicas y Literarias Primer Trimestre de 1954, № 93, pp. 81-86.

\section{N.de R.:}

-Subtítulos entre corchetes cuadrados, dispuestos por Revista de Urbanismo.

-Ilustrado por Revista de Urbanismo, a partir de:

FISCHER, Otto, Arte de India China y Japón, Editorial Labor, S.A., Barcelona, Madrid, Buenos Aires, 1933, 1961.

ED. CODEX S.A., HENDY, Philip (Asesor), El Mundo de los museos: National Gallery of London, 1967.

ED. CODEX S.A., Arte/Rama Enciclopedia de las Artes, 1961.

OTO, Villa d'Este, 1976, Edizioni d'Arte, Roma.

DORLING KINDERSLEY, The complete book of Bonsai, 1990.

Reproducción con fines estrictamente culturales. Revista de Urbanismo es de acceso gratuito. 